\title{
APRESENTAÇÃO DO DOSSIÊ
}

\section{Um perfil geo-histórico de São Paulo e de Lyon (França) do final do século XIX até 1930}

A Revista do Instituto de Estudos Brasileiros tem a oportunidade de publicar a primeira parte de um dossiê de caráter interdisciplinar que resultou da parceria entre algumas unidades da Universidade de São Paulo - USP (Programa de Pós-Graduação em História Social, Laboratório de Estudos de Cartografia Histórica da Cátedra Jaime Cortesão, Programa de Pós-Graduação em Geografia Humana - todos da Faculdade de Filosofia, Letras e Ciências Humanas FFLCH; Pós-Graduação em Arquitetura e Urbanismo da Faculdade de Arquitetura e Urbanismo - FAU; e Programa de Pós-Graduação Culturas e Identidades Brasileiras do Instituto de Estudos Brasileiros - IEB) e a Université Jean Moulin (Lyon 3), especificamente com seu Département de Géographie-Aménagement.

Intitulado "Dinâmicas de urbanização e representações espaciais: abordagem geo-histórica dos territórios com Sistemas de Informação Geográfica (SIG)", o projeto foi aprovado no Edital USP-Cofecub de 20I4. Sua proposta se inseriu no campo da geo-história, área de estudos eminentemente interdisciplinar, que contempla abordagens em diferentes escalas, desde a escala mundial até análises de pequenos sítios históricos. Um recurso interessante nesse campo, e que foi chave na pesquisa, é a construção retrospectiva de realidades histórico-espaciais fazendo uso de técnicas cartográficas. No caso, trata-se de desconstruir mapas históricos, de compreender a difusão dos modelos cartográficos e suas formas de apropriação cultural, identificando as motivações subjacentes na reprodução e circulação dos mesmos: com base nas técnicas da cartografia contemporânea (tecnologia digital com seus Sistemas de Informações Geográficas - SIGs), e a partir do entrecruzamento de diversas fontes de documentação histórica, pode-se conceber mapas retrospectivos que dão visibilidade aos processos de urbanização e transformação das dinâmicas espaciais. Essa nova cartografia digital geo-histórica é resultado do cotejo sistemático de uma multiplicidade de tipologias documentais, visuais e não visuais. As fontes textuais ganham novas possibilidades de identificação de dinâmicas sociais e de 
interpretação quando as narrativas, as informações e os dados que elas trazem se manifestam por meio da linguagem gráfica dos mapas.

Os artigos resultam de dois anos de trabalhos e pesquisas referentes às cidades de São Paulo e de Lyon, na França. A ideia foi a de comparar as dinâmicas e ritmos de crescimento das duas cidades desde finais do século XIX até os anos I930, período no qual elas sofreram transformações estruturais. O objetivo principal da cooperação foi compartilhar experiências sobre métodos de reconstrução geo-histórica dessas cidades. Tais exercícios possibilitaram a espacialização de dados sociodemográficos ainda inéditos, permitindo visualizações de redes que operavam nas cidades, dando oportunidade de rever suas lógicas e impactos.

Convidamos os leitores para apreciar os resultados alcançados nesses dois anos de pesquisa em comum e avaliar conosco a pertinência e a relevância de pesquisas em cooperação e também as possibilidades trazidas pelas práticas cartográficas no campo de geo-história.

\section{Os artigos}

Nesta primeira parte do dossiê estão sendo publicados sete artigos. O primeiro deles é do arquiteto e urbanista Bernard Gauthiez, da Université Jean Moulin Lyon 3. Nele é descrito o método desenvolvido pelo autor nos anos I990 para a análise e o mapeamento de informações sobre as licenças de construção contidas nos arquivos municipais de Lyon, desde o século XVIII. Com isso se consegue a visualização de microespaços, o que dá oportunidade de perceber que o espaço urbano é uma matéria, cuja transformação tem, nos pequenos atores, protagonistas relevantes.

Já o artigo de Olivier Zeller, historiador e professor emérito da Université Lumière Lyon 2, justifica a necessidade de estudos sobre as municipalidades antigas, na escala das médias e pequenas cidades. $\mathrm{O}$ artigo complementa as análises desenvolvidas por Bernard Gauthiez, aprofundando a descrição sobre as jurisdições e gestões municipais responsáveis pelas mudanças ocorridas no espaço urbano de Lyon.

Procurando identificar fenômenos e representações que pesaram na estruturação das cidades, o artigo da geógrafa Virginie Chasles, também da Université Jean Moulin, desenha um perfil da saúde urbana na França e em Lyon a partir das monografias médicas do século XVIII, passando pela revolução pasteuriana e pelo higienismo. Seu objetivo é mostrar como o urbanismo foi influenciado pela medicina. Esse tema é importante para Lyon, pois as transformações levadas a cabo pela administração municipal, observadas por Olivier Zeller e cartografadas por B. Gauthiez, estão diretamente ligadas às ações higienistas.

Completando os artigos relativos à cidade de Lyon, a geógrafa Enali De Biaggi (Université Jean Moulin) trata da produção dos mapas lioneses desde as últimas décadas do século XIX até a terceira década do século XX, concentrando-se no mapeamento em grande escala (com muitos detalhes). Analisa algumas séries topográficas e identifica os aspectos dos mapas que serão a base de outros, e que depois serão utilizados para a gestão de uma cidade em ritmo de crescimento acelerado. As 
informações trabalhadas por ela foram importantes para o desenvolvimento dos trabalhos dos demais pesquisadores do projeto.

Já o bloco de artigos relativos a São Paulo é aberto com texto da historiadora do urbanismo Beatriz Piccolotto Siqueira Bueno, da Faculdade de Arquitetura e Urbanismo da USP, que esclarece o "bota-abaixo" que transformou a cidade de São Paulo - a partir de meados do século XIX - num verdadeiro canteiro de obras. A pesquisadora cruza fontes seriais diacrônicas e sincrônicas, tais como impostos prediais, licenças de construção e legislação, além das informações contidas nos anuários estatísticos, em propagandas de jornais e nas fontes iconográficas.

$\mathrm{O}$ artigo escrito pelos geógrafos Fernanda Padovesi Fonseca, Eduardo Dutenkefer, Luciano Zoboli, da FFLCH-USP, e pelo geógrafo do IEB-USP Jaime Tadeu Oliva apresenta os resultados de um estudo sobre as redes de bondes da cidade de São Paulo de I877 a I930. O trabalho consistiu em georreferenciar mapas antigos procurando responder a um conjunto de interrogações sobre a história geográfica dessa cidade para construir uma base digital geo-histórica. Além do estudo em si, o artigo explicita os procedimentos metodológicos empregados, permitindo a sua utilização como fonte de informação para investigações da mesma natureza.

Por fim, o artigo da geógrafa Eliane Kuvasney, doutoranda da FFLCH, trata da produção cartográfica "oficial” do município de São Paulo nos albores do século XX. No seu texto, ela argumenta que a forma como a cartografia refletia as mudanças nesse período influenciou a dinâmica da cidade e que os ingredientes dessa dinâmica (as ideias de crescimento e expansão, por exemplo) passaram, a partir daí, a ser orientados pelos mapas na medida em que esses eram dotados de competência enunciativa.

Boa leitura!

Íris Kantor (Programa de Pós-Graduação em História Social)

Beatriz Piccolotto Siqueira Bueno (Programa de Pós-Graduação em Arquitetura e Urbanismo da FAU/USP)

Fernanda Padovesi Fonseca (Programa de Pós-Graduação em Geografia Humana)

Eliane Kuvasney (Programa de Pós-Graduação em Geografia Humana)

Jaime Tadeu Oliva (Programa de Pós-Graduação Culturas e Identidades Brasileiras, IEB-USP)

DOI: http://dx.doi.org/Io.II606/issn.23I6-90IX.voi64pI7-I9 